Jurnal Ilmu Sastra

\title{
BINARY OPOSITION IN SARANTUANG BARALIENG KUNYAIT FOLKTALE SITINJAU LAUT KERINCI
}

\section{OPOSISI BINER DONGENG SARANTUANG BARALIENG KUNYAIT DALAM MASYARAKAT SITINJAU LAUT KERINCI}

\author{
Mahawitra Jayawar ${ }^{1}$, Khairil Anwar ${ }^{2}$ \\ ${ }^{1,2}$ Program Studi Magister Sastra Fakultas Ilmu \\ Budaya Universitas Andalas \\ ${ }^{1)}$ Email:j.mahawitra@gmail.com \\ ${ }^{2)}$ Email: khairilanwar@hum.unand.ac.id \\ https://doi.org/10.25077/majis.2020.v2i2.33
}

\begin{abstract}
This study discusses the binary opposition in oral stories of Sarantuang Baraliang Kunyait, which is located in Sitinjau Laut District, Kerinci Regency. Oral literature is in the form of a fairy tale which is still developing in society even though the media has changed, from word of mouth to mouth, now in digital form. This fairy tale tells the story of miscommunication between grandchildren and grandmothers, resulting in tragedy at the end of the story. This fairy tale has a message human and cultural values. To get that value, it is necessary to read it with kualitative methode and out using a deconstruction theory analysis knife. From this study it is found that, these tales have signs of binary opposition, parallelism, and hierarchical reversals.
\end{abstract}

Keywords: fairy tales, binary opposition, deconstructions, signs and meanings

\begin{abstract}
Abstrak
Kajian ini membahas tentang oposisi biner dalam cerita lisan Sarantuang Baraliang Kunyait. Cerita ini terdapat di Kecamatan Sitinjau Laut Kabupaten Kerinci. Sastra lisan tersebut berbentuk dongeng yang masih berkembang di tengah masyarakat walaupun medianya berubah, dari tutur lisan mulut ke mulut. Dongeng ini berkisah tentang miskomunikasi antara cucu dan nenek sehingga terjadi tragedi di akhir kisah. Dongeng ini penting untuk dikaji karena mengandung nilai-nilai kemanusiaan dan kebudayaan. Untuk mendapatkan nilai itu perlu pembacaan dengan metode kualitatif dan analisis dekonstruksi. Dari kajian ini ditemukan bahwa, dongeng tersebut memiliki tanda oposisi biner, paralelisme, dan pembalikan hirarki.
\end{abstract}

Kata kunci: dongeng, oposisi biner, dekonstruksi, tanda, dan makna

\section{PENDAHULUAN}

Sastra lisan merupakan ekspresi pikiran masyarakat suatu tempat atau daerah yang diturunkan atau disebar secara turun temurun dari satu generasi ke generasi selanjutnya. Sastra lisan merupakan tradisi lisan yang berkembang dalam kebudayaan lisan masyarakat pemiliknya yang berupa pesan-pesan, cerita-cerita, dan kejadian-kejadian. Sastra lisan terbagi atas beberapa jenis antara lain cerita rakyat, pantun, dongeng, mitos, dan mantra. Danandjaya mengatakan cerita rakyat adalah suatu bentuk karya sastra lisan yang lahir dan berkembang dari masyarakat tradisional yang disebarkan dalam bentuk relative tetap dan diantara kolektif tertentu dari waktu yang cukup lama dengan menggunakan 


\section{Jurnal Ilmu Sastra}

kata klise (Danandjaya 1997). Cerita rakyat pada umumnya menceritakan suatu kejadian dan situs-situs alam pada tempat tertentu. Tokoh-tokoh yang dimunculkan dalam cerita rakyat umumnya diwujudkan dalam bentuk binatang, manusia, maupun dewa. Tokoh dam cerita tersebut bukan sekedar pelaku dalam alur tetapi diyakini berperan sebagai penjaga situs-situs alam yang diceritakan tersebut (Anwar, Khairil, Ferdinal 2019).

Dongeng (folktale) sebagai bagian dari sastra lisan memiliki fungsi yang beragam di tengah masyarakat. Salah satu fungsi tersebut ialah sebagai media pembelajaran juga sebagai hiburan. Menurut Taylor mengatakan bahwa dongeng juga bisa digunakan untuk mengajarkan moral, tetapi dongeng bukanlah sebuah instrument yang secara sadar digunakan untuk mendidik anak-anak (Allien, Astri Adriani 2010). Dongeng dalam posisi bawah sadar menjadi deep structure yang mengatur interaksi masyarakat satu sama lainnya (Anwar 2018). Oleh karena itu, dongeng secara tidak langsung memberikan pemahaman moral kepada masyarakat pemilik dongeng tersebut.

Salah satu dongeng yang terdapat di tengah masyarakat ialah dongeng Sarantuang Baralieng Kunyait. Dongeng ini menceritakan seorang anak kecil yang bernama Si Putai yang lapar meminta makan kepada neneknya. Akan tetapi Si Putai tidak kunjung diberikan makan setelah berkali-kali meminta kepada neneknya. Akibatnya, ia bersedih hati dan pergi naik ke atas batu untuk menemui orang tuanya di atas Hyang agar neneknya senang atas ketidakhadiran dirinya. Setelah mengetahui Si Putai telah pergi, nenek itu pun meninggal karena sedih dan merasa bersalah kepada cucunya.

Dongeng Sarantuang Baralieng Kunyait ini berasal dan berkembang di Hiang, yang terdiri atas enam desa yaitu Koto Baru Hiang, Hiang Lestari, Hiang Karya, Angkasa Pura, Betung Kuning, dan Hiang Tinggi. Daerah ini berada di Kecamatan Sitinjau Laut Kabupaten Kerinci Provinsi Jambi. Dongeng ini pada umumnya diceritakan oleh orangtua kepada anakanaknya atau oleh kakek dan nenek kepada cucunya.

Pada zaman yang beriontasi pada teknologi digital saat ini, keberadaan dongeng semakin sedikit diceritakan oleh masyarakat pemiliknya. Hal ini terjadi karena kemajuan teknologi yang tempias ke segala lini kehidupan masyarakat. Tradisi bertutur secara lisan mulai berubah ke dalam bentuk tindak tutur melalui ujaran di pesanpesan digital. Untuk itu keberadaan dongeng sangatlah penting untuk diperhatikan, didokumentasikan serta dianalisis supaya menemukan maksud ataupun nilai-nilai yang terdapat di dalam narasi dongeng tersebut.

Dongeng tersebut memiliki nilainilai kemanusiaan dan kebudayaan yang berperan memanusiakan manusia dan meneruskan kebudayaan.Aspekaspek tersebut dapat diungkap melalui pengkajian yang mendalam. Untuk pengkajian ini digunakan teori dekostruksi. Melalui teori dihasilkan makna-makna yang selama ini tidak terjangkau dalam pemahaman makna secara struktural.

\section{METODE PENELITIAN}

Aktor utama dalam dekonstruksi adalah Jacques Derrida, seorang Yahudi Aljazair yang menjadi kritikus sastra dan filsuf. Ia dikenal melalui bukunya yaitu of Grammatology, Speech and Phenomena, dan Writing 


\section{Jurnal Ilmu Sastra}

and Difference. Dekonstruksi Derrida berupaya mengguncang fondasi filsafat. Menurut Amalik, dekonstruksi merupakan kritik tajam terhadap strukturalisme dan dipengaruhi oleh fenomenologi Hussler dan Heidegger (Pujiyanti 2010).

Ratna mengatakan bahwa dekonstruksi merupakan pengurangan atau penurunan intensitas bentuk yang telah tersusun, sebagai bentuk yang baku. Konsep dasar metode ini adalah cara membaca teks yang menghilangkan anggapan bahwa sebuah teks mempunyai landasan, dalam system bahasa yang baku, untuk menegaskan struktur, keutuhan, dan makna yang telah menentu (Ratna 2010).

Derrida menjelaskan bahwa dekonstruksi diawali dengan hal-hal marginal tersubordinasi yang luput dari pikiran atau tidak boleh dipikirkan (Anwar et al. 2010). Dekonstruksi juga dapat dikatakan sebagai penolakan pandangan yang mengatakan bahasa memiliki makna yang pasti serupa yang dilakukan oleh strukturalisme. Dapat dikatakan dekonstruksi merupakan aliran poststrukturalisme. Jika strukturalisme bersifat sistematik, maka poststrukturalisme menolak hal tersebut.

Tujuan yang diharapkan dari metode dekonstruksi ini adalah menunjukkan ketidakberhasilan upaya penghadiran pembenaran yang absolut. Dekontstruksi menelanjangi agenda tersembunyi yang mengandung banyak kelemahan dan kepincangan di balik teks-teks (Pujiyanti, 2010). Culler mengungkapkan bahwa mendekonstruksi suatu wacana (kesastraan) adalah menunjukkan bagaimana meruntuhkan filosofi yang melandasinya, atau beroposisi secara hierarkis terhadap sesuatu yang menjadi landasannya, dengan cara mengidentifikasi bentuk-bentuk operasional retorika yang ada dalam teks itu, yang memproduksi dasar argument yang merupakan konsep utama (Nurgiyantoro 2007). Dengan kata lain, dekonstruksi menolak makna umum yang dianggap ada dalam suatu teks sastra.

Ratna mengatakan dalam dekonstruksi dilakukan semacam pembongkaran, tetapi tujuan akhir yang hendak dicapai adalah penyusunan kembali ke dalam tatanan dan tatanan yang lebih signifikan yang sesuai dengan hakikat objek, sehingga aspek-aspek yang dianalisis dapat dimanfaatkan semaksimal mungkin. Kristeva menjelaskan bahwa dekonstruksi merupakan gabungan antara hakikat dekstruktif dan konstruktif (Ratna 2010).

Teori poststrukturalisme cukup sulit untuk dipahami, cara yang dilakukan untuk mengatasinya adalah, pertama, memahaminya sesuai dengan akar leksikal, kedua, memahami terlebih dahulu akar permasalahannya, yaitu konsep-konsep kunci teori-teori terdahulu yang dianggap sebagai penyebab pokok lahirnya poststrukturalisme. Tujuan pokok poststrukturalisme adalah mendekonstruksi strukturalisme (Ratna 2010).

Inti dari teori Derrida adalah perbedaan (differance), untuk itu disebut sebagai teori perbedaan. Puji Yanti mengatakan differance mencakup dua pengertian yaitu to differ yang berarti membedakan diri dari, dan to defer yang berarti menunda. Differance menurut Derrida hanya dipahami lewat tulisan, bukan tuturan (Pujiyanti 2010). Dengan kata lain difference adalah rekonstruksi dari hasil dekontstruksi.

Menurut teori bahasa Derrida (Zulfadhli 2009) penanda (signifier) 


\section{Jurnal Ilmu Sastra}

tidak berkaitan langsung dengan petanda (signified). Petanda dan penanda tidak berkorespondesi satusatu. Menurut pemikiran Saussure, tanda dilihat sebagai satu kesatuan, tetapi menurut Derrida, pada kenyataannya kata dan benda atau pemikiran tidak pernah menjadi satu. Derrrida melihat tanda sebagai struktur perbedaan: sebagian darinya selalu "tidak di sana", dan sebagian yang lain selalu "bukan yang itu". Dengan kata lain, Derrida mengatakan ketika membaca suatu penanda, makna tidak serta merta menjadi jelas. Penanda menunjuk apa yang tidak ada, maka dalam arti tertentu makna juga tidak ada. Makna terus-menerus bergerak di sepanjang mata rantai penanda, dan tidak dapat dipastikan "posisi" persisinya karena makna tidak pernah terikat pada satu tanda tertentu.

Syafrina (Syafrina 2014) mengatakan dalam teori dekonstruksi Derrida kita akan sering sekali bertemu dengan istilah logos yang menurut Derrida merupakan suatu impian atau keinginan untuk membentuk suatu makna yang tunggal dalam sebuah teks. Logos selalu mencari pusat yang stabil dari sebuah teks sehingga terbentuklah satu kebenaran akhir yang nilainya mutlak. Logos juga disebutkan sebagai simbol kehadiran yang menjadi dominan dalam sebuah teks sastra. Oleh karena itu, dekonstruksi Derrida mencoba untuk menolak akan adanya logos dalam sebuah teks, Derrida beranggapan bahwa tidak ada pemaknaan tunggal dalam sebuah teks, sehingga sifat Logos tersebut menjadi ambigu akibat munculnya pemaknaan-pemaknaan baru.

\section{HASIL DAN PEMBAHASAN}

\section{Oposisi Biner}

Faruk mengatakan bahwa langkah utama dalam melakukan analisis menggunakan teori dekonstruksi Derrida adalah mencari dan menemukan oposisi berpasangan yang terdapat dalam teks sastra tersebut (Syafrina 2014). Hal ini dilakukan untuk menemukan perbedaan dan pertentangan yang merupakan sifat asli teks tersebut. Pertentangan dapat diumpamakan seperti siang dan malam, hitam dan putih, lelaki dan perempuan yang memiliki karakter saling berlawanan tetapi memiliki keterikatan antara yang satu dengan yang lain.

Dongeng Sarantuang Baralieng Kunyait merupakan cerita rakyat yang dikategorikan ke dalam sastra lisan. Pada dongeng ini ditemukan beberapa oposisi biner, yaitu antara tokoh $\mathrm{Si}$ Putai dengan tokoh nenek. Si Putai merupakan cucu tokoh nenek dalam dongeng ini. Si Putai digambarkan sebagai seorang cucu yang mengingingkan makan kepada nenek. Sehingga dalam cerita ini Si Putai diperlihat sebagai tokoh yang baik dan berusaha meminta makan kepada neneknya. Akan tetapi neneknya tersebut tidak memberinya makan. Kehadiran tokoh nenek yang terlihat berkarakter inilah yang membuat $\mathrm{Si}$ Putai menjadi tokoh yang baik.

Dari hubungan oposisi di atas, pembaca digiring untuk menjadikan tokoh Si Putai sebagai logos atau penunggalan makna, yaitu tokoh yang memiliki karakter baik. Untuk itu dilakukan usaha untuk menjadikan tokoh Si Putai sebagai logos dan dibentuklah tesis-tesis yang mendukung cerita, karena dongeng ini merupakan sastra lisan. Tokoh Si Putai dihidupkan sebagai karakter baik yang akan membuat pendengar ataupun pembaca akan bersimpati.

Dalam dongeng ini pada bagian awal diceritakan bahwa Si Putai merupakan seorang yatim piatu 


\section{Jurnal Ilmu Sastra}

sehingga ia hidup hanya bersama neneknya. Suatu ketika Si Putai merasa kelaparan dan meminta makan kepada neneknya diiringi senandung, seperti kutipan berikut.

Si Putai tinggal bersama neneknya. Jadi, sewaktu ibunya meninggal, bapaknya meninggal ia tinggal bersama nenek. Apa katanya kepada nenek.

"Sarantuang baralieng kunyait minta nasi ke nenek". "Tunggu aku mencangkul"

Gambaran kemalangan kehidupan Si Putai diperlihatkan dengan jelas di dalam cerita ini. Hal tersebut tampak dari kutipan di atas bahwa untuk meminta makan saja ia harus beribaiba memohon kepada neneknya tersebut. Kemudian, kemalangan hidup $\mathrm{Si}$ Putai didukung oleh pernyataan yang menceritakan bahwa ia hanya hidup berdua dengan neneknya karena kedua orang tuanya telah meninggal. Oleh karena itu, sebagai seorang anak yang masih belia, kebutuhan hidup Si Putai sangat bergantung kepada neneknya itu. Hal ini merupakan tesis yang digunakan untuk menarik simpati.

Penggambaran cerita yang terdapat di awal memberikan maksud untuk membuat pembaca ataupun pendengar cerita akan bersimpati kepada tokoh Si Putai. Akan tetapi, usaha untuk menarik simpati pendengar atau pembaca tidak hanya terjadi di awal cerita saja. Pada bagian berikutnya, kemalangan tokoh Si Putai terus dimunculkan. Si Putai diceritakan menangis menahan lapar dan seolah-olah akan mati akibat menahan lapar tersebut. Sementara itu ia tidak kunjung diberi makan oleh neneknya itu. Badannya telah kurus dan duduk di atas batu. Ibu telah meninggal bapaknya telah meninggal dan tinggal bersama nenek yang telah tua. Tidak berapa lama dikatakannya lagi pada neneknya.

"Sarantuang baralieng
kunyait minta nasi kepada
nenek"
"Tunggu menyiang padi"

Kemalangan $\mathrm{Si}$ Putai yang menangis akibat menahan lapar hebat di atas menunjukkan tesis yang akan menambah simpati pembaca. Sedangkan citra negatif terhadap perlakuan buruk nenek didapatkan melalui tindakan nenek yang tampak seolah-olah menunda-nunda untuk memberi makan kepada cucunya tersebut.

Kemudian, tesis lain yang menunjukan oposisi baik-buruk dalam cerita adalah menunjukkan citra positif tokoh dominan dan menampilkan citra buruk tokoh minor. Seperti yang terdapat di dalam cerita, Karena tidak kunjung diberi makan oleh neneknya. Putai bersenandung kepada batu yang ia duduki agar bertemu dengan orang tuanya disurga. Pendengar maupun pembaca diarahkan untuk memahami bahwa tokoh Si Putai ingin melakukan itu agar neneknya tidak lagi merasa direpotkan karena mengurusi kehidupan Si Putai. Lihat kutipan berikut.

Setelah menanak.

Cucu tadi telah iba

hati dan duduk di

atas batu di bawah

rumah. Apa kata

cucunya.

"Tinggi-tinggi kau

batu biar senang hati

nenek" Meninggilah

batu itu sedepa

sampai dua depa. 


\section{Jurnal Ilmu Sastra}

Jadi, neneknya tadi

masih berada di

rumah tidak juga

mengurus cucunya.

Menangis pulalah

cucunya.

"Tinggi-tinggi kau

batu biar senang hati

nenek".

Sampailah batu itu

setinggi bubung atap.

Berbeda dengan tokoh Si Putai, tokoh nenek ditampilkan memiliki citra buruk. Hal ini ditampilkan dari tindakan nenek yang selalu menunda member makan kepada cucunya dengan mengatakan jika ia harus ke sawah terlebih dahulu, mencangkul, menyiang padi, memanen, menumbuk padi, bahkan menanak nasi. Sementara itu Si Putai ditampilkan telah menangis dan hampir mati akibat menahan lapar yang cukup lama.

Pertentangan yang terjadi dalam cerita dongeng ini untuk memudahkan pembaca maupun pendengar untuk menentukan tokoh yang baik dan tokoh yang buruk dalam cerita. Karakter tokoh yang buruk akan mempermudah pembaca atau pendengar untuk membentuk simpati kepada tokoh yang dominan.

\section{Paralelisme}

Dalam dongeng Sarantuang Baralieng Kunyait, logos terdapat cerita yang membawa pembaca atau pendengar agar memaknai tokoh $\mathrm{Si}$ Putai menjadi tokoh yang berkarak terbaik sementara nenek adalah tokoh yang beroposisi dan memiliki karakter yang buruk. Melalui kedua tokoh tersebut cerita akan mengarahkan pendengar ataupun pembaca untuk melihat karakter baik tokoh dominan dan keburukan tokoh minor dari awal cerita hingga akhir cerita. Tesis-tesis yang terdapat pencerita. Dengan demikian, pencerita akan lebih mudah untuk mengarahkan pendengarnya maupun pembacanya sesuai dengan keinginannya, yaitu membuat makna tunggal dalam cerita.

Dalam kehidupan nyata, peran nenek ataupun orang tua adalah mengurusi segala kehidupan anak dan cucunya. Hal ini membentuk wacana universal yang mempengaruhi pendengar ataupun pembaca. Karena wacana ini akan mempengaruhi proses berpikir pendengar atau pembaca dengan menyamakan apa yang terdapat di dalam cerita dengan realitas kehidupan yang ada di dunia nyata. Oleh karena itu akan muncul pemaknaan tunggal sehingga menutup kesejajaran antara tokoh dominan dan tokoh minor yang ada dalam cerita.

Jika diperhatikan lebih jauh, apabila logos dikesampingkan. Kekurangan yang terdapat pada tokoh dominan akan terkuak sekaligus cerita akan menampilkan sisi baik yang dimiliki oleh tokoh minor. Oposisi biner yang menempatkan Si Putai yang ditempatkan sebagai tokoh yang dominan karena sisi baiknya akan tampak tidak baik seperti yang diinginkan pencerita. Sebaliknya sisi buruk nenek yang terdapat dalam cerita juga tidak akan seburuk yang ada dalam cerita.

Sifat baik yang dimiliki Si Putai membentuk kesan negatif. Si Putai digambarkan sebagai tokoh yang lemah, tokoh yang menderita karena kelaparan. Ia meminta kepada tokoh nenek. Seperti yang terdapat dalam cerita bahwa kedua orang tua Si Putai telah meninggal dan ia hanya tinggal bersama neneknya. Untuk itu tentu nenek memiliki segala keterbatasan dalam upaya untuk memenuhi kebutuhan cucunya tersebut. Ketika Si Putai merasa lapar, mengapa ia hanya memohon kepada nenek agar diberikan 


\section{Jurnal Ilmu Sastra}

makanan. Mengapa tokoh Si Putai tidak membantu nenek untuk mencari bahan makanan. Hal ini justru memperlihatkan sisi negative dari tokoh Si Putai yang terkesan manja dan enggan membantu neneknya itu.

Pemaknaan tunggal dalam cerita telah mengaburkan sifat baik yang dimiliki oleh nenek yang telah berusaha ke sawah, mencangkul, menanam padi hingga menanak nasi untuk cucunya tersebut. Seorang yang telah tua renta dengan keterbatasan tenaga justru melakukan pekerjaan kasar sebagai upaya untuk memenuhi kebutuhan cucunya.

Penjelasan di atas menampilkan sifat baik dan buruk yang dimiliki oleh tokoh dominan dan tokoh minor yang beroposisi dalam cerita membentuk penyetaraan di antara kedua tokoh tersebut. Tokoh Si Putai digambarkan memiliki sifat baik akan tetapi juga memiliki sifat yang buruk, begitupun sebaliknya.

Berdasarkan paralelisme yang muncul di dalam dongeng Sarantuang Baralieng Kunyait, tesis-tesis yang muncul sebelumnya dibangun oleh pencerita akhirnya menghancurkan dirinya sendiri. Kemalangan tokoh dominan tidak lagi membuat pendengar atau pun pembaca bersimpati dan menempatkan tokoh minor sebagai pelaku buruk yang terdapat dalam cerita. Begitupun halnya dengan sifat positif yang dimiliki tokoh dominan membuatnya lebih tinggi dibandingkan tokoh minor menjadi kabur setelah adanya kesejajaran baik-buruk antara kedua tokoh tersebut. Hal ini dikarenakan dekonstruksi menolak pemaknaan tunggal, teks yang terbuka dapat memberikan pemahaman lain ataupun kemungkinan lain untuk menemukan makna tersembunyi yang terdapat di dalam cerita.

\section{Pembalikan Makna}

Pada dongeng Sarantuang Baralieng Kunyait, kehadiran makna lain dapat ditemukan setelah dilakukannya pembalikan terhadap hierarki yang ada sebelumnya dalam cerita. Pembalikan makna hierarki telah mengaburkan makna tunggal yang terdapat dalam cerita. Makna yang sebelumnya dianggap fixed ternyata menghancurkan dirinya sendiri, termasuk makna yang tertunda.

Pembaca maupun pendengar secara tidak langsung menganggap tokoh dominan sebagai tokoh yang baik dan tokoh yang minor juga memiliki karakter yang baik. Begitupun dengan karakter buruk yang dimiliki oleh kedua tokoh. Dengan dilakukannya analisis menggunakan teori dekonstruksi ini ternyata menimbulkan pemahaman baru bahwa tidak sepenuhnya tokoh yang terlihat buruk memiliki karakter yang buruk.

Kajian dekonstruksi terhadap karya sastra sudah banyak dilakukan, terutama karya-karya sastra modern, karena karya tersebut dianggap representasi kekinian zaman yang beriringan dengan mucul dan lahirnya teori tersebut. Teori tersebut dianggap cocok dengan karya-karya yang tumbuh dan berkembang dengan berbagai bentuk yang miskin makna.

Berbeda dengan anggapan bahwa karya-karya klasik dan tradisonal merupakan karya yang mencerminkan kemapanan yang sesuai dengan struktur social. Karya-karya tersebut dianggap bagian dari alat control social. Pada hal dalam karya klasik tersebut terdapat juga hal-hal marginal dan tersubordinasi yang dianggap tidak penting dan berusaha dikaburkan, tetapi sesungguhnya memiliki makna dan nilai bagi pembangunan totalitas kehidupan masyarakatnya, seperti 


\section{Jurnal Ilmu Sastra}

kajian terhadap dongeng Sarantuang Kunyait.Kajian seperti ini menjadi penting untuk mengungkapkan kedalaman makna yang terkandung dalam cerita-cerita dan dongeng rakyat. Hal itu tidak dipahami oleh masyarakat tetapi secara tidak sadar menjadikannya sebagai bagian dari norma yang mengatur kehidupan mereka.

\section{SIMPULAN}

Pada dongeng Sarantuang Baralieng Kunyait ditemukan satu oposisi biner yaitu tokoh $\mathrm{Si}$ Putai sebagai tokoh yang dominan dan tokoh nenek sebagai tokoh minor. Tokoh dominan merupakan upaya pencerita untuk membangun pemaknaan tunggal sebagai upaya menarik simpati pembaca atau pendengar melalui kejadian kemalangan yang dialami oleh $\mathrm{Si}$ Putai sekaligus membentuk citra buruk terhadap nenek. Namun, setelah dilakukan penyelasaran dan pembalikan hierarki Kedua tokoh sama-sama memiliki karakter baik dan buruk. Makna inilah yang sebelumnya tersembunyi dalam cerita ini. Artinya, dalam setiap tubuh terdapat unsur baik dan buruk, dominannya salah satu menyebabkan hilangnya keberadaan yang lain.

\section{UCAPAN TERIMA KASIH}

Akhirnya, terima kasih disampaikan kepada Universitas Andalas yang telah memberikan kesempatan kepada penulis untuk melajutkan studi ke jenjang yang lebih tinggi melalui Program Studi Magister Ilmu Sastra, Program Pascasarjana Fakultas Ilmu Budaya dan kepada Jurnal Magistra Andalusia: Jurnal Ilmu Sastra yang memberikan kesempatan kepada penulis untuk mengungkapkan ide dan pikiran melalui artikel ilmiah dalam terbitannya.

\section{DAFTAR PUSTAKA}

Allien, A. A. dan Inosensia D. J. 2010. "Dongeng The Sleeping Beauty: Analisis Fungsi Menurut Vladimir Propp." Atavisme Vol 13, No.

Anwar, K., Ferdinal, Rima D. 2019. "Inyiak and Marvin Harris Keepers of Tradition Oral And Ecology: Challenges in the Era of Oil Palm Plantation Expansion in West Sumatra." In Sciendo. Proceeding of The 13th International Conference on Malaysia-Indonesia Relations (PAHMI)., Padang: Sciendo, 14753.

Anwar, K. 2018. "Ecological Wisdom of Oral Tradition: Surface and Deep Structure Tension in Preserving the Lake Environment." In IOP Conference Series: Earth and Environmental Science, Volume 469, International Conference on Environment and Technology 1011 August 2018, Unive, Grafitiperss.

Anwar, K., I Wayan Cika, I Nyoman Kutha Ratna, and I Nyoman Weda Kusuma. 2010. "Bagurau: Minangkabau Oral Literature In Luhak Nan Tigo West Sumatera." e-Journal of Linguistic (Vol. 4. Juli 2010 No. 2).

Danandjaya, J. 1997. Folklore Indonesia, Ilmu Gosip Indonesia. Jakarta: Grafitiperss.

Nurgiyantoro, B. 2007. Teori Pengkajian Fiksi. Yogyakarta: Gajah Mada University Press. 


\section{Jurnal Ilmu Sastra}

Pujiyanti, F. 2010. Dekonstruksi Dominasi Laki-Laki Dalam Novel The Da Vinci Code Karya Dan Brown. Semarang: Universitas Diponegoro.

Ratna, N. K. 2010. Sastra Dan Cultural Studies: Representasi Fiksi Dan Fakta. Yogyakarta: Pustaka Pelajar.

Syafrina, R. 2014. "Analisis Dekonstruksi Terhadap Tiga Dongeng Grimms Bersaudara: Rapunzel, Snow Drop, Dan Ashputtel." Diglossia: Jurnal Kajian Ilmiah Vol 6, No: 34-51.

Zulfadhli. 2009. "Dekonstruksi Dalam Cerpen Malin Kundang, Ibunya Durhaka Karya A.A. Navis." Jurnal Bahasa dan Seni Vol 10 No: hlm132-137. 